\title{
Non-enzymatic assay for glucose by using immobilized whole-cells of E. coli containing glucose binding protein fused to fluorescent proteins
}

\author{
Ana Charneca ${ }^{a}$, Amin Karmali ${ }^{\mathrm{a}, *}$, Manuela Vieira ${ }^{\mathrm{b}}$ \\ ${ }^{a}$ Chemical Engineering and Biotechnology Research Center and Departmental Area of Chemical Engineering of Instituto Superior de Engenharia de Lisboa, \\ R. Conselheiro Emídio Navarro, 1, 1959-007 Lisboa, Portugal \\ ${ }^{\mathrm{b}}$ Electronics Telecommunication E' Computer Department of Instituto Superior de Engenharia de Lisboa, R. Conselheiro Emídio Navarro, 1 , \\ 1959-007 Lisboa, Portugal
}

\section{A R T I C L E I N F O}

\section{Article history:}

Received 23 June 2014

Received in revised form 5 June 2015

Accepted 5 June 2015

Available online 20 June 2015

\section{Keywords:}

Fluorescent indicator proteins

Onion membranes

Genetically encoded nanosensor $3.2 \mathrm{mM}$

High throughput glucose assay

Immobilization on 96-well microtiter plates FRET

\begin{abstract}
A B S T R A C T
Glucose monitoring in vivo is a crucial issue for gaining new understanding of diabetes. Glucose binding protein (GBP) fused to two fluorescent indicator proteins (FLIP) was used in the present study such as FLIP-glu- 3.2 mM. Recombinant Escherichia coli whole-cells containing genetically encoded nanosensors as well as cell-free extracts were immobilized either on inner epidermis of onion bulb scale or on 96well microtiter plates in the presence of glutaraldehyde. Glucose monitoring was carried out by Förster Resonance Energy Transfer (FRET) analysis due the cyano and yellow fluorescent proteins (ECFP and EYFP) immobilized in both these supports.

The recovery of these immobilized FLIP nanosensors compared with the free whole-cells and cell-free extract was in the range of 50-90\%. Moreover, the data revealed that these FLIP nanosensors can be immobilized in such solid supports with retention of their biological activity. Glucose assay was devised by FRET analysis by using these nanosensors in real samples which detected glucose in the linear range of $0-24 \mathrm{mM}$ with a limit of detection of $0.11 \mathrm{mM}$ glucose. On the other hand, storage and operational stability studies revealed that they are very stable and can be re-used several times (i.e. at least 20 times) without any significant loss of FRET signal. To author's knowledge, this is the first report on the use of such immobilization supports for whole-cells and cell-free extract containing FLIP nanosensor for glucose assay. On the other hand, this is a novel and cheap high throughput method for glucose assay.
\end{abstract}

(c) 2015 Elsevier B.V. All rights reserved.

\section{Introduction}

Glucose is an important physiological analyte involved in major catabolic pathways such as glycolysis and oxidative phosphorylation. Therefore, the maintenance and regulation of glucose concentration are critical issues for proper physiological function [1]. Continuous blood glucose monitoring is a key issue of modern diabetes treatment, particularly in type 1 diabetes as well as insulin-dependent type 2 diabetes [2]. The search for the ideal glucose sensor has been a long-time goal of many researchers and as a result, many glucose sensors have been developed in the last few decades [3]. Although many glucose sensing systems have found in vivo applications, the need for a reliable, specific, sensitive and stable glucose sensor is highly required [4]. There are many parameters that affect the development of an optimized glucose sensor such as selectivity, linear range, biocompatibility,

\footnotetext{
* Corresponding author. Tel.: +351 21831 7052; fax: +351 218317267

E-mail address: akarmali@deq.isel.ipl.pt (A. Karmali).
}

response time, reproducibility and reversibility of signal [5]. Moreover, these enzyme electrodes are based on a chemical conversion [6] with a consumption of glucose and $\mathrm{O}_{2}$ and production of hydrogen peroxide and D-gluconic acid in vivo. A promising alternative to electrochemistry has been investigated by several research groups which is fluorescence-based glucose sensing $[2,7,8]$. This is a powerful method suitable for fast, sensitive, reagentless, and non-invasive detection of neutral analytes such as glucose [7-9].

Glucose binding protein (GBP) has been used for glucose sensing by several research workers [8]. Mature genetically engineered GBP was fused to enhanced yellow fluorescent protein (EYFP) and enhanced cyano fluorescent protein (ECFP) containing histidine affinity tag for glucose sensing in plants [10]. The levels of glucose were quantified by Fluorescence Resonance Energy Transfer (FRET) measurements which allow the determination of ratio of emission intensity of EYFP/ECFP [11]. Although several research workers have used these genetically encoded nanosensors for glucose assay, they were used in a soluble and purified form [10]. In the last decade, there is an increasing interest on whole-cell biosensors [12-14] since microbial cells can be genetically manipulated to be 
used as whole-cell biosensors for a wide range of biomolecules in order to optimize the sensitivity, selectivity and robustness. On the other hand, the nature of immobilization supports used and the high throughput assay method are also critical issues for a good glucose biosensor.

Therefore, the present work involves the immobilization of recombinant whole-cells and cell-free extract containing genetically encoded biosensors on onion membranes and 96-well microtiter plates. These nanosensors will be used for glucose assay either in free or immobilized forms.

\section{Materials and methods}

\subsection{Chemicals}

Glutaraldehyde, Coomassie Blue dye, 96-well tissue culture microtiter plates (polystyrene), imidazole, ampicillin, glucose oxidase and peroxidase were purchased from Sigma-Aldrich (St. Louis, MO, USA). LB medium components were supplied by HiMedia Laboratories (Mumbai, India). Onions were obtained from a local supermarket. All other chemicals used were of analytical grade.

\subsubsection{Recombinant plasmids containing genetically encoded} glucose nanosensors

Recombinant plasmids containing FLIP-glu- $3.2 \mathrm{mM}$ was obtained from Addgene, USA. This nanosensor had a dissociation constant (Kd) of $3.2 \mathrm{mM}$ for glucose [15].

\subsection{Methods}

\subsubsection{Maintenance and growth conditions of recombinant Escherichia coli strains}

Recombinant plasmid containing FLIP-glu- $3.2 \mathrm{mM}$ was used to transform $E$. coli strains and the recombinant strains were grown in solid Luria Bertani (LB) medium containing $100 \mu \mathrm{g} / \mathrm{ml}$ ampicillin of culture medium at $37^{\circ} \mathrm{C}$ for $24 \mathrm{~h}$ in order to obtain single colonies.

\subsubsection{Production of fluorescent indicator protein (FLIP)}

nanosensors

The production and extraction of FLIP nanosensors from recombinant E. coli was carried out as described previously with major modifications [10]. Briefly, single colonies of recombinant E. coli containing FLIP-glu- $3.2 \mathrm{mM}$ were grown in LB medium containing $100 \mu \mathrm{g} / \mathrm{ml}$ ampicillin in the dark at $21^{\circ} \mathrm{C}, 150 \mathrm{rpm}$ for $2-3$ days. The cells were harvested by centrifugation at $10,000 \mathrm{rpm}$ for $5 \mathrm{~min}$ at $4{ }^{\circ} \mathrm{C}$, washed with saline and centrifuged again at same speed. The supernatant was discarded and the pellet was stored at $-20^{\circ} \mathrm{C}$.

The cells were thawed, resuspended in 2 volumes of $20 \mathrm{mM}$ Tris- $\mathrm{HCl}$ buffer $\mathrm{pH} 8.0$ containing $1 \mathrm{mM}$ benzamidine and sonicated at $4{ }^{\circ} \mathrm{C}$ for $30 \mathrm{~s}$, for three times and centrifuged at $19,000 \mathrm{rpm}$ for $1 \mathrm{~h}$. The supernatant was recovered and used as the cell-free extract which was a source of FLIP nanosensors.

\subsubsection{Immobilization of FLIP glucose nanosensors}

As far as immobilization on inner epidermis of onion bulb scale is concerned, it was carried out as published previously with major modifications [16]. Preliminary experiments were carried out in order to optimize several parameters such as the amount of wholecells, cell-free extract, concentration of glutaraldehyde and drying time on the support. Briefly, circular membrane of the epidermis were cut (5-10 mm diameter) and suitable aliquots of recombinant $E$. coli cells and cell-free extracts in $20 \mathrm{mM}$ Tris-HCl buffer $\mathrm{pH}$ 8.0 containing $1 \mathrm{mM}$ benzamidine were transferred to these membranes, dried for $1 \mathrm{~h}$ at room temperature. A suitable amount of glutaraldehyde $(8 \mu \mathrm{l})$ was added to the membrane and incubated at room temperature for $45 \mathrm{~min}$. Subsequently, membranes were washed several times with $20 \mathrm{mM}$ Tris- $\mathrm{HCl}$ buffer $\mathrm{pH} 8.0$ containing $1 \mathrm{mM}$ benzamidine and stored in the same buffer at $4{ }^{\circ} \mathrm{C}$. As far as fluorescence measurements are concerned, these membranes were transferred to a 96-well microtiter plate containing $200 \mu \mathrm{l}$ of $50 \mathrm{mM}$ phosphate buffer $\mathrm{pH} 7.0$ containing $1 \mathrm{mM}$ benzamidine per well and readings were carried out in a microtiter plate reader. These membranes were stored at $4{ }^{\circ} \mathrm{C}$ in the same buffer system and they were re-used several times. Regarding the immobilization of whole-cells and cell-free extracts on tissue culture 96-well microtiter plates, suitable aliquots of these biosensors were transferred to these plates and dried overnight at room temperature. Subsequently, appropriate concentration of glutaraldehyde $(20 \mu \mathrm{l})$ was added to the wells and the same procedure was followed as described above. These microtiter plates were stored at $4{ }^{\circ} \mathrm{C}$ in the same buffer system and they were re-used several times.

\subsubsection{Spectra measurement of free and immobilized glucose nanosensors}

Fluorescent measurements were carried out either on spectrofluorimeter (JASCO FP- 8300 in a quartz cuvette) or on Fluorstar Optima microtiter plate reader (excitation: $433 \mathrm{~nm}$ and emission: $485 \mathrm{~nm}$ and $528 \mathrm{~nm}$ ) in $100 \mu \mathrm{l}$ of $50 \mathrm{mM}$ phosphate buffer $\mathrm{pH} 7.0$ containing $1 \mathrm{mM}$ benzamidine per well as described previously with major modifications [10]. Briefly, measurements were carried out in the Spectrofluorimeter (Jasco) and spectra were obtained in $50 \mathrm{mM}$ phosphate buffer $\mathrm{pH} 7.0$ containing $1 \mathrm{mM}$ benzamidine $(100 \mu \mathrm{l})$ as the background. Increasing concentrations of glucose $(0.01,0.1,1.0$ e $10 \mathrm{mM})$ in the same buffer system were added to the soluble forms of cell-free extract or whole-cells $(100 \mu \mathrm{l})$ containing the glucose nanosensor. The same procedure was carried out for the immobilized glucose nanosensor on circular membrane and on 96-well microtiter plates and spectra were measured either in the wavelength range of $400-600 \mathrm{~nm}$ (Spectrofluorimeter) or in microtiter plate reader (excitation: $433 \mathrm{~nm}$ and emission: $485 \mathrm{~nm}$ and $528 \mathrm{~nm})$.

\subsubsection{Glucose assay}

FRET analysis was calculated as the ratio of the fluorescence intensity at $528 \mathrm{~nm}$ divided by the fluorescence intensity at $485 \mathrm{~nm}$. Spectra measurements were carried out of the free form of both nanosensors in the presence and absence of glucose as the ligand. The presence of glucose alters the fluorescence intensity of the yellow (530 nm) and cyano ( $485 \mathrm{~nm}$ ) of FLIP nanosensors. The spectra measurements were carried out by using free and immobilized forms of both nanosensors in the presence and absence of glucose as the ligand. A calibration curve for glucose was carried out by using FRET measurements in the linear range of 0-24 mM glucose as described in Section 2.2.4. For comparative purposes, glucose was assayed in several samples of human sera by using the present FRET method and a conventional colorimetric assay method based on glucose oxidase and peroxidase [6].

\subsubsection{Stability of immobilized FLIP glucose nanosensors}

Immobilized FLIP glucose nanosensors (microtiter plates and onion membranes) were used to investigate their storage and operational stabilities. Therefore, fluorescence measurements were carried out in the presence and absence of glucose in order to determine their stability as a function of time by measurements of glucose assay in microtiter plate reader. These nanosensors were stored in $50 \mathrm{mM}$ phosphate buffer $\mathrm{pH} 7.0$ containing $1 \mathrm{mM}$ benzamidine at $4{ }^{\circ} \mathrm{C}$.

\subsubsection{Selectivity of genetically encoded nanosensors}

The selectivity of these nanosensors was investigated by using several carbohydrates as ligands in order to study their effect on the 
ratio of EYFP/ECFP compared with the glucose by using different ligand concentrations.

\subsubsection{Protein assay}

Protein concentration of cell-free extracts were carried out by coomassie blue dye binding method by using BSA as the protein standard as mentioned previously with minor modifications [17].

\section{Results and discussion}

\subsection{Production of genetically encoded glucose nanosensors}

Genetically-encoded FRET nanosensors have been developed for measuring the dynamic changes in concentration of several metabolites of biological interest [10]. The present FRET sensor contains GBP which was fused to a fluorescent pair with overlapping emission and excitation spectra (i.e. ECFP and EYFP). The binding of the metabolite of interest induces a conformational change that affects the relative distance and/or orientation between the two fluorescent proteins which can cause either an increase or a decrease in FRET efficiency. These FLIP nanosensors were detected in LB culture medium by measurement of fluorescence spectrum between 400 and $600 \mathrm{~nm}$ (Fig. 1A) since there are two fluorescence peaks at about 485 and $530 \mathrm{~nm}$. Moreover, the fluorescence spectrum of cell-free extract of FLIP-glu- $3.2 \mathrm{mM}$ nanosensor was obtained in the presence and absence of glucose which revealed a decrease in fluorescence of EYFP and an increase of ECFP as shown in Fig. 1B.

\subsection{Immobilization of FLIP glucose nanosensors}

The 96-well tissue culture microtiter plates and onion membranes were selected as immobilization supports since they exhibited the best results as far as recovery and retention of biological activity are concerned. The cell wall of inner epidermis cells contains several biological macromolecules such as polygalacturonic acid, hemicelluloses, proteins and lignin [18]. Therefore, onion membranes exhibit a biocompatible microenvironment and stable support for immobilization of whole-cells and cell-free extract.

The immobilization of these nanosensors on both these supports resulted in recovery of fluorescence in the range of 50-90\% which was represented as the percentage of the ratio EYFP/ECFP compared with the free form of the nanosensor (Figs. 2 and 3).

As far as glutaraldehyde is concerned, several concentrations were tested and it was found that lower concentrations of glutaraldehyde exhibited higher recovery of fluorescence of either the immobilized whole-cells or cell-free extract on both supports (Fig. 2). The effect of the amount of whole-cells and cell-free extract on fluorescence recovery at a constant concentration of glutaraldehyde (i.e. $2 \%, v / v$ ) was also investigated which revealed that lower amounts of nanosensor exhibited higher recovery of fluorescence of either the immobilized whole-cells or cell-free extract on both supports (Fig. 3). Therefore, these data indicate that the rate-limiting step seems to be the low capacity of the onion membranes as well as the wells of the microtiter plates $[16,18]$.

\subsection{Glucose assay}

Glucose assay was carried out by using free and immobilized genetically encoded nanosensor in the range of $0-100 \mathrm{mM}$ as shown in Fig. 4. As expected, the ratio of EYFP/ECFP decreased as the glucose concentration increased for the free form of the nanosensor for whole-cells and cell-free extract (Fig. 4A). The cellfree extract presented higher FRET values than whole-cells because it has a higher amount of soluble protein compared with the

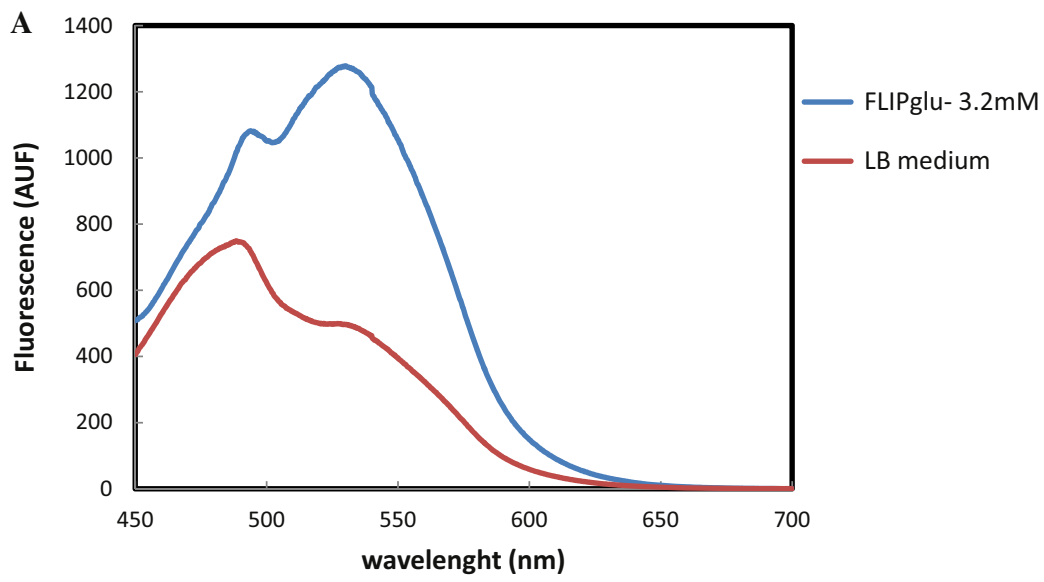

B

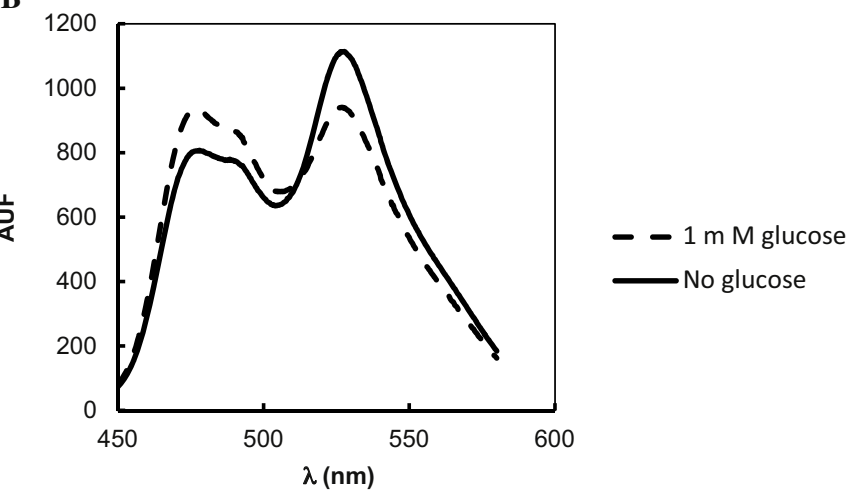

Fig. 1. Spectra of whole-cells and cell-free extract. (A) Whole-cells; (B) cell-free extract in the presence and absence of glucose. 

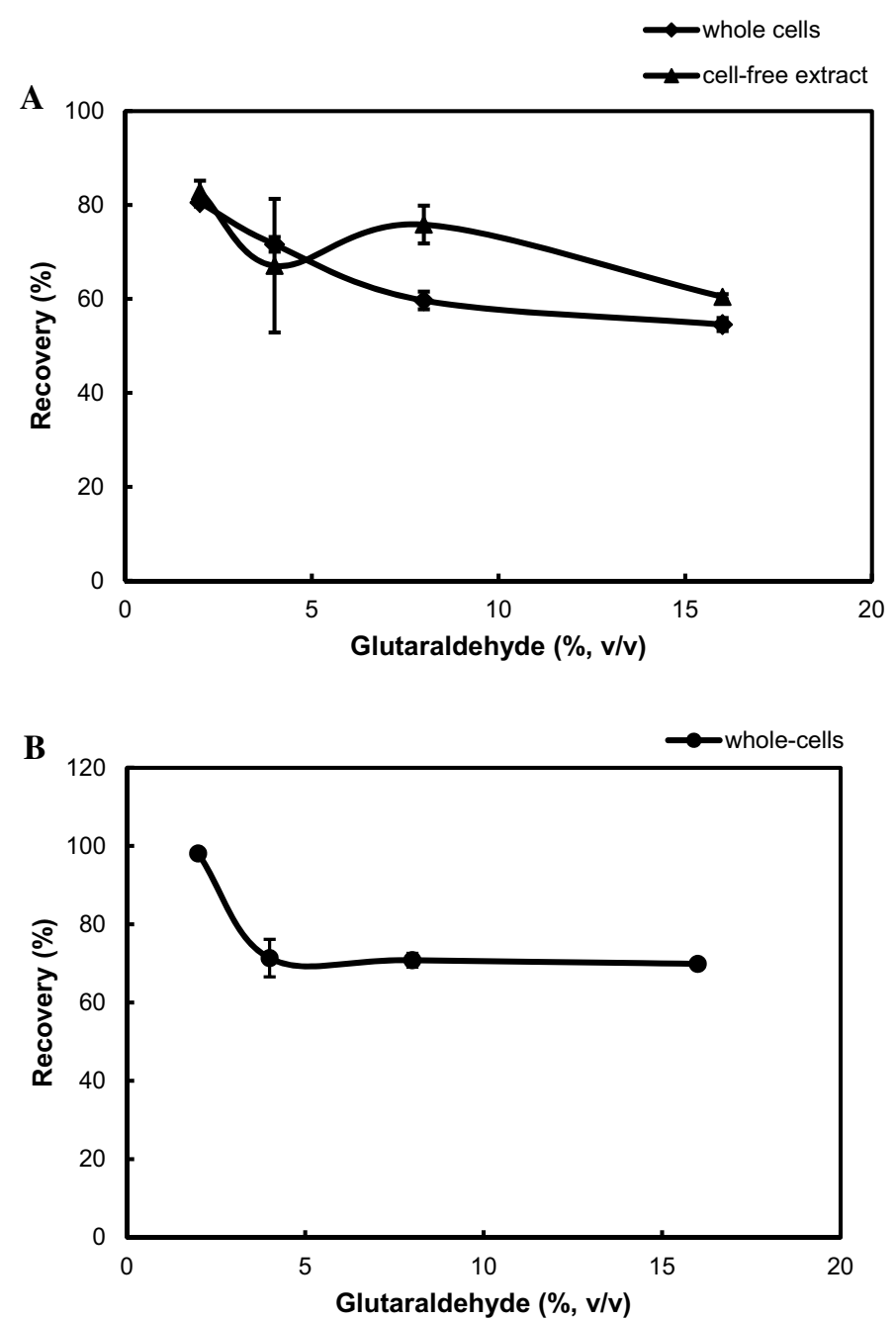

Fig. 2. Effect of glutaraldehyde concentration on the recovery of glucose nanosensor immobilized on both supports. A constant amount of whole-cells ( 1.9 and $0.5 \mu \mathrm{g})$ and cell-free extract $(2.9$ and $29.0 \mu \mathrm{g}$ ) of FLIP-glu- $3.2 \mathrm{mM}$ were used and glutaraldehyde concentration was varied for onion membrane and tissue culture plate, respectively. The recovery represents percentage of the ratio EYFP/ECFP in the presence of glucose compared with the free form of the biosensor. (A) Inner epidermis of onion bulb scale; (B) 96-well tissue culture microtiter plate.

whole-cells (Fig. 4A). Moreover, the nanosensor in cell-free extract and whole-cells may be in different conformations which has been also mentioned by other research workers in the literature $[12,19]$. However, as far as the immobilized cell-free extract and wholecells on onion membrane are concerned, the data revealed an increase in the ratio as a function of glucose concentration which suggest that there is an increase in FRET efficiency (Fig. 4B). Similar results were also obtained with immobilized nanosensors in 96-well microtiter plates (data not shown). This result was unexpected but it may be explained by the fact that the covalently immobilized nanosensor is bound to the immobilization support in such a way that both fluorescent proteins (i.e. EYFP and ECFP) may be located further apart. Subsequently, the binding of glucose to GBP induces a conformational change which may apparently bring closer both these two fluorescent proteins and therefore there is an increase in FRET efficiency. Several research workers have reported that FRET is apparently a very complex process when free and immobilized whole-cells or cell-free extracts are involved [19-22]. Regarding the differences in FRET efficiencies between the free and immobilized nanosensors, there are a number of factors affecting immobilized and soluble proteins such as
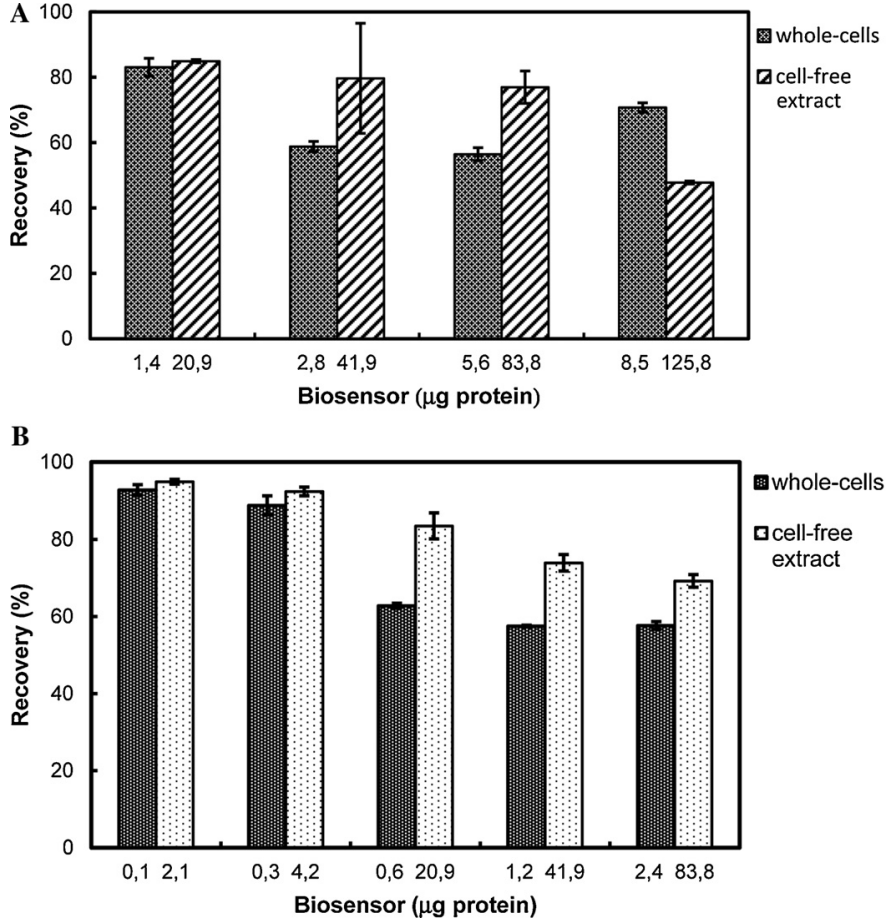

Fig. 3. Effect of the amount of whole-cells and cell-free extract on the recovery of glucose nanosensor immobilized on both supports. Increasing amounts of wholecells and cell-free extract of FLIP-glu- $3.2 \mathrm{mM}$ were used at a constant concentration of glutaraldehyde (2\%). The recovery represents percentage of the ratio EYFP/ECFP in the presence of glucose compared with the free form of the biosensor. (A) 96-well tissue culture microtiter plate; (B) inner epidermis of onion bulb scale.

restricted mobility on immobilization, chemical modification due to the immobilization method used, nature of the microenvironment and diffusion limitation [20]. There are several reports in the literature that have mentioned different fluorescent behavior in the FRET pair between free and immobilized nanosensors due to some factors mentioned above. Apparently, this difference may be due to the reduced flexibility of the linker domain between the fluorescent proteins because of the attachment to solid surface. This issue emphasizes the importance to retain flexibility of both the fusion proteins in devising FRET pairs for immobilization to solid surfaces [19,21]. In general, FRET theory assumes that in a FRET couple only a single donor and a single acceptor are present with very weak coupling. However, in cell-free extracts or wholecells, it is generally unknown if a single or multiple acceptors are present which markedly complicates the calculation of FRET efficiency. Moreover, other problems must be evaluated and controlled such as cross-talk between FRET partners, effect of $\mathrm{pH}$ on their microenvironment and difference in stoichiometric ratios of donor and acceptor biomolecules [23,24]. However, this immobilized nanosensor was successfully used to assay glucose in real samples of human sera (Table 1 ). A calibration curve for glucose assay has been presented in Fig. 4C by using immobilized cell-free extract on onion membrane. A limit of detection (LOD) of $0.11 \mathrm{mM}$

Table 1

Comparative analysis of glucose assay by the present FRET method (i.e. immobilized whole-cells in onion membrane) and conventional colorimetric method by using three different human sera samples.

\begin{tabular}{lll}
\hline Serum samples & $\begin{array}{l}\text { Present FRET } \\
\text { method }(\mathrm{mM})\end{array}$ & $\begin{array}{l}\text { Colorimetric } \\
\text { method }(\mathrm{mM})\end{array}$ \\
\hline Human serum 1 & $3.1 \pm 0.15$ & $3.3 \pm 0.11$ \\
Human serum 2 & $5.9 \pm 0.32$ & $6.1 \pm 0.28$ \\
Human serum 3 & $8.4 \pm 0.43$ & $8.7 \pm 0.51$ \\
\hline
\end{tabular}




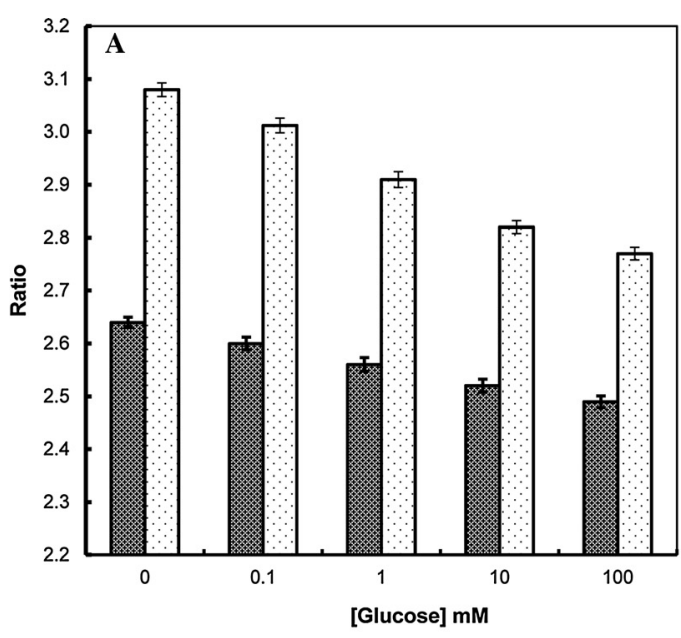

Whole-cells 口Cell-free extract
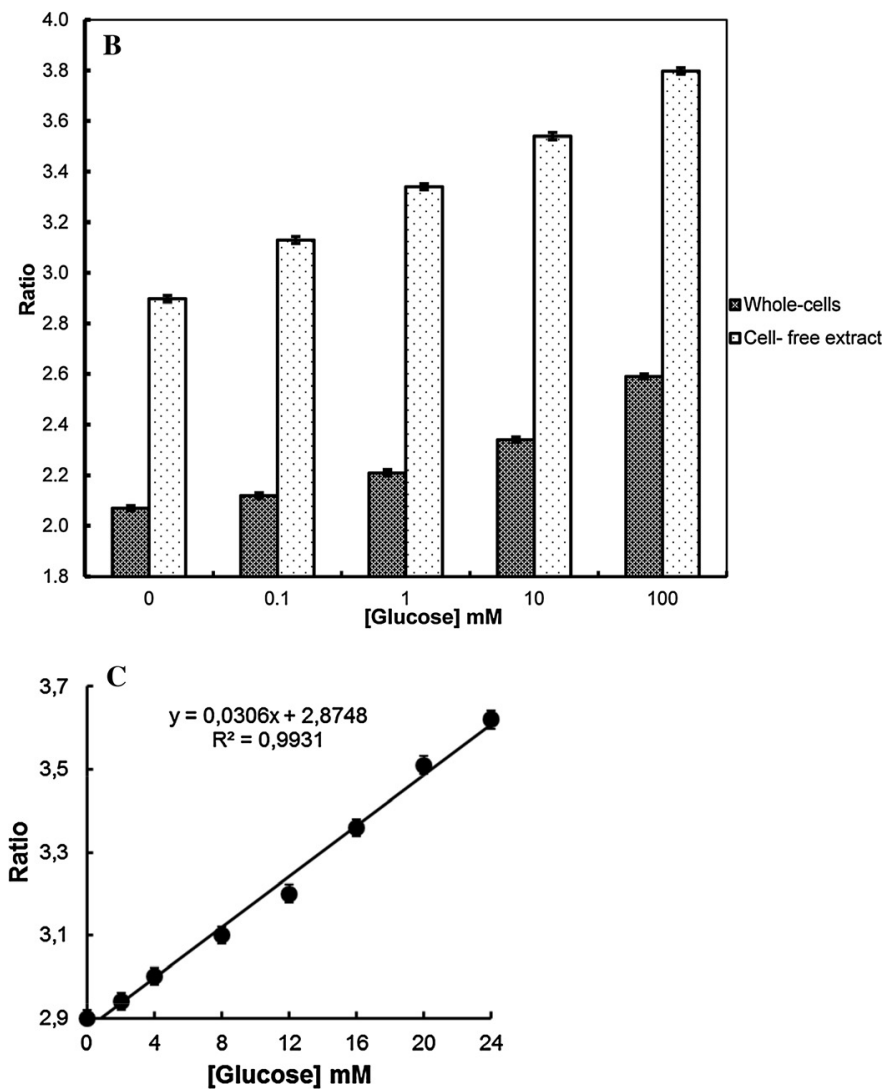

Fig. 4. Effect of glucose concentration on the ratio of EYFP/ECFP of free and immobilized FLIP-glu- $3.2 \mathrm{mM}$ nanosensor. (A) Free whole-cells and cell-free extract; (B) immobilized cell-free extract and whole-cells on onion membrane and (C) calibration curve for glucose assay by using immobilized cell-free extract on onion membrane.

glucose was obtained according to IUPAC and ICH [25]. However, upconversion luminescence nanosensors have been used to assay for glucose with a LOD of $64 \mathrm{nM}$ which is much lower than the value presented in this work [26]. A comparative study was carried out by using a well-established conventional colorimetric assay for glucose with glucose oxidase and peroxidase which revealed that the results are slightly lower with the FRET method compared the colorimetric method (Table 1 ). These results may be explained by the fact that some interfering substances in human serum may affect the FRET method. However, this difference is not significant since very similar results were obtained for both methods (Table 1 ).
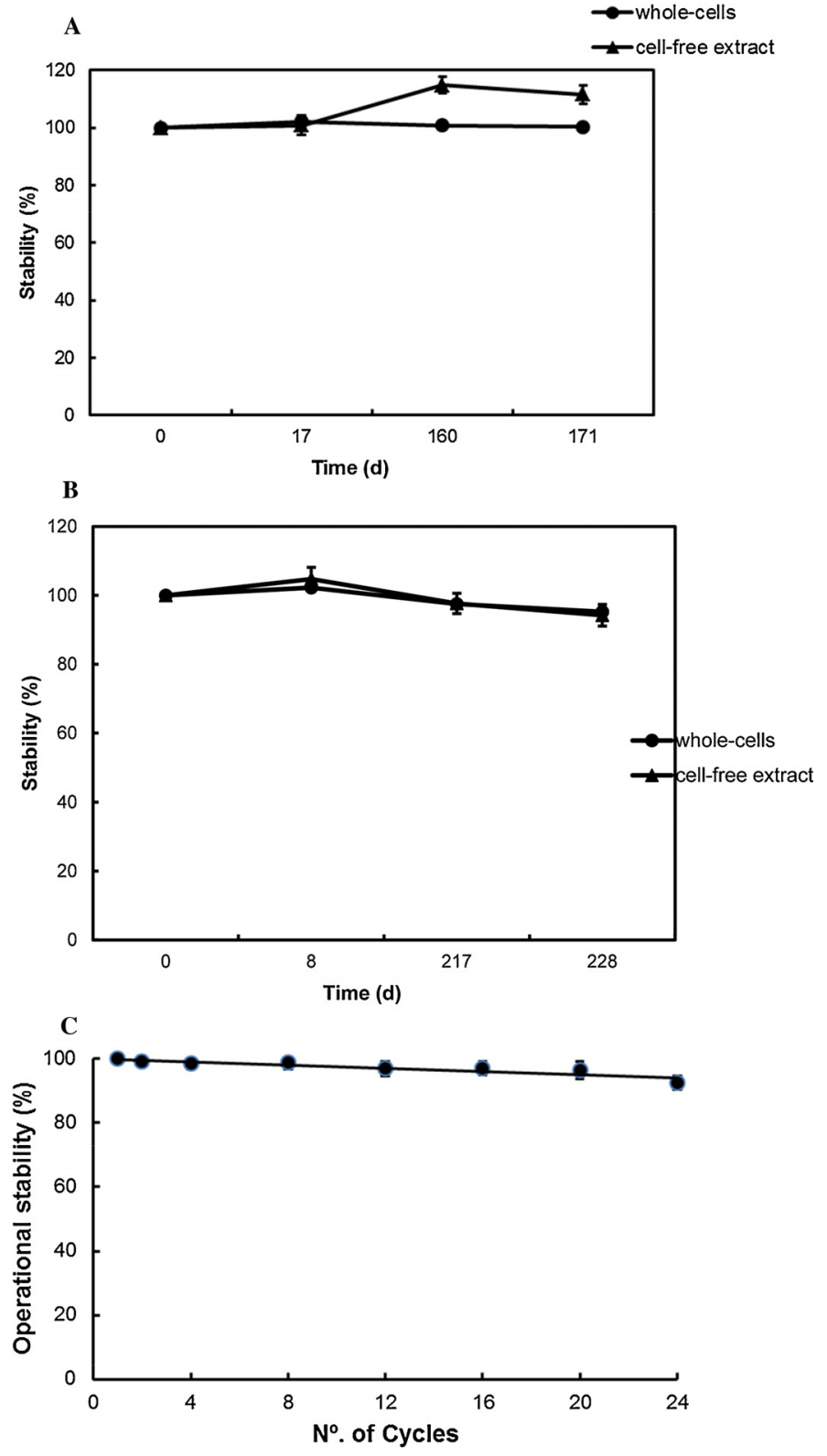

Fig. 5. Stability of whole-cells and cell-free extract containing FLIP-glu- $3.2 \mathrm{mM}$ nanosensor immobilized on both supports. The stability/operational stability represents the percentage of the ratio EYFP/ECFP in the presence of glucose as a function of time: (A) inner epidermis of onion bulb scale; (B) 96-well tissue culture microtiter plate and (C) Operational stability of the immobilized nanosensor on onion membrane as a function of No. of cycles for glucose assay.

Similar results were obtained by using immobilized whole-cells and cell-free extract on 96-well microtiter plates (data not shown).

\subsection{Stability of immobilized FLIP glucose nanosensors}

The data presented in Fig. 5 revealed that the immobilized nanosensors exhibited a very high storage stability at $4{ }^{\circ} \mathrm{C}$ of over 6 and 7 months for onion membrane and tissue culture microtiter plate, respectively (Fig. 5A and B). On the other hand, the operational stability of these immobilized nanosensors was also investigated by assaying for glucose as a function of the number of cycles which revealed that they could be used at least 20 cycles without any significant loss of biological activity as far as FRET signal is concerned (Fig. 5C). 


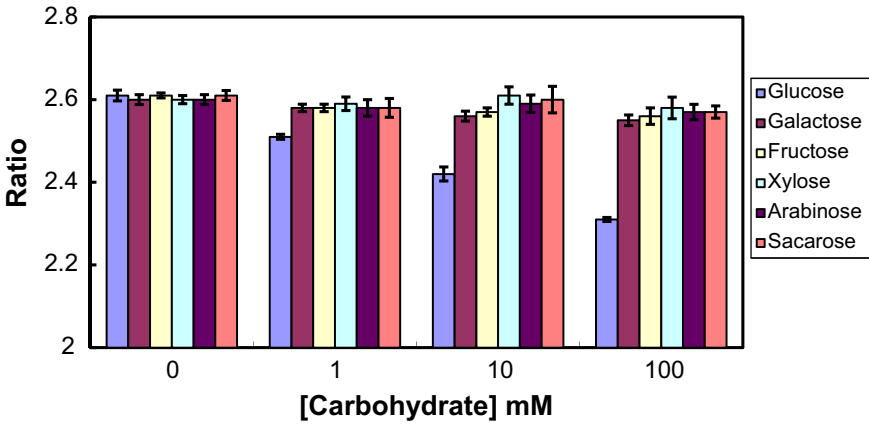

Fig. 6. Selectivity of FLIP-glu- $3.2 \mathrm{mM}$ nanosensor. Different concentrations of several sugars were used to investigate their effect on the ratio by using free whole-cells.

\subsection{Selectivity of genetically encoded nanosensors}

The selectivity of FLIP-glu- $3.2 \mathrm{mM}$ nanosensor was investigated by using several mono and disaccharides on the ratio which revealed that galactose exhibited a very small cross-reactivity with the nanosensor compared with the glucose (Fig. 6). This result is in agreement with published reports on the selectivity of these genetically encoded nanosensors [10].

\section{Conclusions}

Recombinant E. coli whole-cells and cell-free extract containing genetically encoded nanosensors were immobilized on onion membrane and tissue culture microtiter plates with high recovery of biological activity. This method was used to quantify glucose in real human sera samples and the results are in agreement with a well-established colorimetric assay method. This assay method is based on 96-well microtiter plate which can be used as a high throughput assay method for glucose since it is cheap, rapid and many samples can be assayed on a single platform. The storage and operational stability of these nanosensors are high and therefore they can be re-used several times. To author knowledge, this is the first report on the use of immobilized whole-cells and cell-free extract containing genetically encoded nanosensors for glucose assay by using these two novel supports.

\section{Acknowledgements}

We would like to thank Fundação para a Ciência e a Tecnologia/ MCTES (Portugal) for financial support (PTDC/EEA-ELC/11854/ 2009; Pest 2012-2014 for Unit 702).

\section{References}

[1] M. Taguchi, A. Ptitsyn, E.S. McLamore, J.C. Claussen, Nanomaterial-mediated biosensors for monitoring glucose, J. Diab. Sci. Technol. 8 (2014) 403-411.

[2] J.C. Pickup, F. Hussain, N.D. Evans, O.J. Rolinski, D.J. Birch, Review Fluorescencebased glucose sensors, Biosens. Bioelectron. 20 (2005) 2555-2565.

[3] A.P.F. Turner, Biosensors: sense and sensibility (Tutorial Review), Chem. Soc. Rev. 42 (2013) 3184-3196.

[4] J.V. Veetil, S. Jin, K. Ye, A glucose sensor protein for continuous glucose monitoring, Biosens. Bioelectron. 26 (2010) 1650-1655.

[5] E.A. Moschou, B.V.Sharma, S.K. Deo, S. Daunert, Fluorescence glucose detection: advances toward the ideal in vivo biosensor. J. Fluoresc. 14 (2004) 535-547.

[6] C. Chen, Q. Xie, D. Yang, H. Xiao, Y. Fu, Y. Tan, S. Yao, Recent advances in electrochemical glucose biosensors: a review, RSC Adv. 3 (2013) 4473-4491.

[7] S.B. VanEngelenburg, A.E. Palmer, Fluorescent biosensors of protein function, Curr. Opin. Chem. Biol. 12 (2008) 60-65.
[8] R. Ballerstadt, J.S. Schultz, A galactose-specific affinity hollow fiber sensor based on fluorescence resonance energy transfer, Meth. Biotechnol. 7 (2000) 89-98.

[9] T. Saxl, F. Khan, D.R. Matthews, Z-L. Zhi, O. Rolinski, S. AmeerBeg, J. Pickup, Fluorescence lifetime spectroscopy and imaging of nano-engineered glucose sensor microcapsules based on glucose/galactose-binding protein, Biosens. Bioelectron. 24 (2009) 3229-3234.

[10] M. Fehr, S. Lalonde, I. Lager, M.W. Wolff, W.B. Frommer, In vivo imaging of the dynamics of glucose uptake in the cytosol of COS-7 cells by fluorescent nanosensors, J. Biol. Chem. 278 (2003) 19127-19133.

[11] M. Fehr, W.B. Frommer, S. Lalonde, Visualization of maltose uptake in living yeast cells by fluorescent nanosensors, Proc. Natl. Acad. Sci. U.S.A. 99 (2002) 9846-9851.

[12] G. Wen, X.Wen, S. Shuang, M.M.F. Choi, Whole-cell biosensor for determination of methanol, Sens. Actuators B 201 (2014) 586-591.

[13] M. Park, T.-L. Tsai, W. Chen, Microbial biosensors: engineered microorganisms as the sensing machinery, Sensors 13 (2013) 5777-5795.

[14] A.R. Barbosa, A. Karmali, Development of a biosensor for urea assay based on amidase inhibition, using an ion-selective, Biocatal. Biotransform. 29 (2011) $130-140$.

[15] K. Deuschle, S. Okumoto, M. Feh, L.L. Looger, L. Kozhukh, W.B. Frommer, Construction and optimization of a family of genetically encoded metabolite sensors by semirational protein engineering, Protein Sci. 14 (2005) 2304-2314

[16] J. Kumar, S.F. D'Souza, Immobilization of microbial cells on inner epidermis of onion bulb scale for biosensor application, Biosens. Bioelectron. 26 (2011) 4399-4404.

[17] J.J. Sedmak, S.E. Grossberg, A rapid, sensitive and versatile assay for protein using Coomassie Brilliant Blue G-250, Anal. Biochem. 79 (1977) 544-552.

[18] J.J. Kumar, S.F. D’Souza, Inner epidermis of onion bulb scale: as natural support for immobilization of glucose oxidase and its application in dissolved oxygen based biosensor, Biosens. Bioelectron. 24 (2009) 1792-1795.

[19] B.G. Abraham, V. Santala, N.V. Tkachenko, M. Karp, Fluorescent protein-based FRET sensor for intracellular monitoring of redox status in bacteria at single cell level, Anal. Bioanal. Chem. 406 (2014) 7195-7720.

[20] L.Q. Zhou, A.E.G. Cass, Periplasmic binding protein based biosensors 1. Preliminary study of maltose binding protein as sensing element for maltose biosensor, Biosens. Bioelectron. 6 (1991) 445-450.

[21] R.M. De Lorimier, Y. Tian, H.W. Hellinga, Binding and signaling of surfaceimmobilized reagentless fluorescent biosensors derived from periplasmic binding proteins, Protein Sci. 15 (2006) 1936-1944.

[22] H-C. Ishikawa-Ankerhold, R. Ankerhold, G.P.C. Drummen, Review advanced fluorescence microscopy techniques-FRAP, FLIP, FLAP, FRET and FLIM, Molecules 17 (2012) 4047-4132.

[23] D.M. Chudakov, M.V. Matz, S. Lukyanov, K.A. Lukyanov, Fluorescent proteins and their applications in imaging living cells and tissues, Physiol. Rev. 90 (2010) 1103-1163.

[24] D.W. Piston, G.-J. Kremers, Fluorescent protein FRET: the good the bad and the ugly, Trends Biochem. Sci. 32 (2007) 407-414.

[25] Y. Hayashi, R. Matsuda, K. Ito, W. Nishimura, K. Imai, M. Maeda, Detection limit estimated from slope of calibration curve: an application to competitive ELISA, Anal. Sci. 21 (2005) 167-169.

[26] J. Liu, L. Lu, A. Li, J. Tang, S. Wang, S. Xu, L. Wang, Simultaneous detection of hydrogen peroxide and glucose in human serum with upconversion luminescence, Biosens. Bioelectron. 68 (2015) 204-209.

\section{Biographies}

Ana Charneca completed her Bachelor degree in Chemical and Biological Engineering in 2012 at Instituto Superior de Engenharia de Lisboa (ISEL) in Portugal and since then she has been involved in research activities as a research assistant in a biosensor research project for glucose. She has several publications in international journals as well as in international scientific conferences.

Amin Karmali got his Ph.D. at the age of 26 from King's College London- U.K., and postdoctorate from Gulbenkian Institute of Science in Portugal. He got his D.Sc (aggregation) in 2001 at Évora University. He is a full Professor in Bioengineering and Head of Biotechnology and Chemical Engineering Research Center of ISEL in Lisbon, has several research projects funded by European and National Research Council, has supervised 15 M.Sc. and 7 Ph.D. thesis (completed), published more than 70 papers and 4 patents in reputed journals and is a reviewer of several international journals and editorial member of some journals.

Manuela Vieira was born in Lisbon, Portugal. In 1986, she received the Masters of Science in solid state physics-microelectronic and in 1993 the Ph.D. in semiconductor materials both from the New University of Lisbon. She is full professor in electronics in the Department of Electronics Telecommunication and Computers (ISEL, Portugal) and the head of a group in applied research in microelectronic optoelectronic and sensors (GIAMOS). She has several scientific papers and 20 years of experience in the field of thin films and devices, her research activities have been mainly related to the development of optical sensors. 